\title{
Research on the relationship between scenic spots and Aboriginal issues
}

\author{
Hu Huang ${ }^{1, a^{*}}$ \\ 1 Guangdong Vocational Institute of Science and Technology,Zhuhai, China. \\ ahuangh98@163.com
}

Keywords:Scenic area; Aboriginal; protection; harmonious

Abstract. With the rapid development of tourism, scenic area has gradually become the destination of choice for most tourists. But the rapid development in scenic areas at the same time, the problem of the harmonious relationship between area and the Aborigines have become increasingly prominent, seriously affected the sustainable development of the scenic areas. This paper analyze the problem of the relationship between scenic spots and indigenous people, and puts forward some measures about the scenery and the harmonious development of the aboriginal protection scenic spot area, so as to provide a reference for the social problems of scenic area control.

\section{Derivation of the problem}

Since the reform and opening, with the high-speed development of economy and the continuous improvement of people's living standard, people's consumption concept has been changed. The resort has become part of the ordinary people's life. As an opportunity, and by all levels of government in tourism is "smokeless factory" as an important content of stimulating local economy. Tourism for prompting booming tourism economy, from the world cultural and natural heritage sites to the provincial national scenic area, heritage from material to non-material heritage, celebrity zone to the local folk customs, from... A full bloom, everything. At the same time, the native living in places of scenic spot in the face of visitors flocked from all directions in the tour consumption, in the process of tourist visitors during the period of specific consumer psychology, in general, tourists are holding the money up with the joneses "mentality, very different from home life consumption idea, naturally, the idea of" communities depend, on the sea ". Therefore, the use of their own some of the original living facilities, make small business phenomenon appeared. Generally displays in: one is to open the inn, hostel, hotel, eat for tourists; Second, in their own homes or village then some small tourist souvenirs, local products such as; 3 it is to sell labor such as taxi, carry slide, bamboo raft, to do a tour guide, etc. Some scenic spots in the temple also unwilling to lag behind, joined the star-studded operating force. although this has convenient visitors, promote prosperity in the scenic area, increasing the income of the parties to the side, but if it is not regulated, it did, is bound to be natural and cultural landscape in the scenic spot is not harmonious situation of coordination and even destructive role.

Based on this, the author choose some cases through field investigation, this paper present situation and existing problems in the current scenic area, to analytical thinking, to establish their own train of thought, to carry out research, trying to provide reference to management decision makers, can make the scenic area construction toward conducive to ecological protection, as well as the profit of all aspects in the direction of healthy development.

\section{Investigation of present situation}

i) The new premises overbuilt, uncoordinated and the natural landscape and the village of the original unity of rhyme flavor.

In the construction of new countryside, especially one of the problems is how traditional context structure retained in the modern environment, namely its relationship with modern buildings around how to deal with the problem. Living people because of the economic benefits of tourism in the scenic spot and the impact of the 
modern way of life, have built new buildings, but because of the lack of overall planning and design, due to new and existing homes not harmonious, we often encounter a very prestigious history and culture in the construction of a village which has the function of modern building or buildings, cause for an entire village. Such as north guangdong shaoguan danxia mountain scenic area, residential building and the scenic area.

ii) Tourism infrastructure projects regardless of the scenic area of natural and historical cultural characteristic.

The problem of blind construction of humanistic landscape prominent, inappropriate development and construction of scenic spots to make resources damage, buried. To enhance regional economic development and tourism development tide, many local governments will be the development of mining and utilization of scenic spot of humanism tourism resources as a magic weapon of economic interests and enhancing the construction. Because of the large system will not the development of tourism resources and scenic areas of the original residents into the regional tourism development, no overall planning, co-ordination arrangements, the using resource of single form similar, geographical dispersion, low grade, the problem of repeated development and construction, thus the lack of tourist market appeal, it is difficult to form a cluster effect and scale effect. For example, once caused a hot debate of Zhangjiajie elevator, construction and a number of hotels, service facilities, in the vigorous development of tourism policy under the guidance of the original vegetation development vigorously deforestation, land used for construction of service facilities, so that some of the original has natural and cultural tourism resources have been seriously damaged.

iii) Randomintegration of different religions, some Buddhist or Taoist holy land into a hodgepodge, so that the original feature loss. Some scenic spots as the holy land of Taoism is to build Buddhist temples, such as the famous attractions of Fujian Jiuli Lake Taoist cents to make pills of immortality to become holy Qi dream, now the expansion of the scale is huge, imposing pressure aisle view Buddhist jungle pattern Jiuxian temple, the original is lost.

iv) Jump to expand the size of the temple. To some of the little and dainty for the characteristics of the scenic area was full of small hills, buildings, small streams by large buildings oppression and extrusion lost to space and height.

v) Pastoral is a scenery line, such as the Guangxi terrace in Longsheng to "terrace" was listed as a world heritage site, such as mutual reflect rape flowers and the ancient villages of Jiangxi Wuyuan and the formation of a unique landscape, due to the excessive development of the local government, many scenic landscape value with Tian garden occupied or destroyed. In addition, Aboriginal instead engaged in related to the tourism economy occupation, make pastoral abandoned, overgrown with weeds, or bare land, again also could not find the characteristic of the agricultural society. Make the city people to enjoy the pastoral scenery tourist area, do not feel the history.

vi) Trains, ancient Bridges the old transport facilities are an integral part of the overall traffic. Some scenic spots for the construction of a new traffic facilities, the bearing the history of civilization, full of a quality suggestive of poetry or painting the landscape was put aside, no function after long-term gradually ignored, let it have its swing is destroyed and cannot be protected.

vii) Government departments, Aboriginal, scenic spot in the temple three party for the distribution of benefits arising to seize resources phenomenon is more prominent and widespread, formed to interests at the expense of serious consequences to the destruction of the natural, human landscape at the expense of.

\section{Cause analysis}

i) The benefit actuation and produce management contradictions, the ultimate damage is the protection and development of scenic spots. Can bring remarkable economic benefits in the tourism at the same time, also inevitably brings negative effect, of which the most important is the people the pursuit of interests, ignoring the concomitant problems of environment. Tourism resources development too fast, bring some pressure on the surrounding environment and infrastructure, and some modern artificial architecture and with the original 
natural ecological landscape dominated by highly coordinated, resulting in scenic areas lost its original natural ecological beauty, city phenomenon, reducing the original landscape aesthetic value. The original village town, New Town Street widening, formed continuously, the production and business activities have become increasingly active, the increasingly serious environmental pollution, scenic resource value gradually decreased. Some scenic areas into downtown, cause the past pure and elegant "fairyland" scene no longer exists. These residents rely mostly on scenic resources and its tourism economic benefits to survive, because the market stimulation, increasing demand and the intensity of resource development, to the scenic areas of social stability, ecological environment and resource protection and reasonable utilization caused great threat, resulting in social contradictions and problems with the development of landscape the scenic area will become more prominent, serious threat to the sustainable development of scenic areas.

ii) On the indigenous peoples attention to the lack of planning of scenic areas, caused by the differences of opinion, different attitude. Our country is current and relevant theories of scenic areas planning and whether the protection or use are "see things but not people", often only pay attention to the material content, and ignore the human factor, planning and management often on physical space planning, and students' social problems, residents in the protection of state scenic area attention is often lacking, social adjustment and control of residents only as a secondary item study without a proper role for the overall planning. Furthermore, the existing planning mainly depended on experts and scholars, is taken to be a top-down process, planning is completed by regulatory agencies to implement, as one of the planning of the heir of the original residents, in the planning process is lack of the right to participate fully, they only passive acceptance, coupled with the management institutions and their lack of communication that led to the planning of the implementation process, not to the understanding and support of residents or residents of the host government, the implementation effect is greatly reduced.

iii) Between the management of scenic spots and Aboriginal contradiction. The laws and regulations of our country, scenic area residents not to acquire ownership of resources, even local residents for several generations of farming land will not belong to all people, and the managers and developers have the resources of scenic areas of ownership and management. In the processing of scenic resource protection and tourism development problems, managers often starts with the migration of local residents, but how to transfer rarely consider the needs of residents. From the scenic area in the relocation of residents, due to the actual situation of the residents is not enough and there are all sorts of contradictions, or long-term residents to cultivate the land was sold to develop or designated as protection areas, but residents of the loss has not been a corresponding compensation etc.. So now the management of scenic spots and residents existed in the scenic resource protection and utilization and the distribution of benefits of the sharp contradiction.

\section{Coping strategies}

i)In the original ecological protection principle. Rational use of existing resources for the purpose, take the sustainable development as the goal, is dominated by the government to do a comprehensive planning. Relying on the natural environment in the scenic area, the formation of tourism resources in the process of ascension to the optimization of natural environment, the tourism industry and the cause of environmental protection has a natural coupling and the development of convergence. The protection of scenic spots value is inseparable from the environment, production and life and the environment and resources of Aboriginal and closely related, is the foundation of its development. If the cause of the destruction of the ecological environment in tourism development, Aboriginal is directly bear the negative consequences, forced to pay cannot use the ecological resources of the "opportunity cost", it will cause the opposition and indigenous tourismenterprises and the scramble for resources, which in turn will aggravate the damage to the ecological environment, form vicious circle. The development of tourism enterprises in tourism resources, the construction of tourist facilities, shall be in accordance with the tourism resource development, utilization and 
conservation planning, is conducive to ecological and environmental protection, landscape and scenic protection.

ii) Combing the relationship, taking into account the interests of, the formation of mutual tolerance to overall situation of the atmosphere. Including the implementation of remediation planning, scenic area, the demolition of buildings, reducing the reduction, the construction of the building, the repair, make the landscape and buildings to form a whole. According to the theory of social communication, individual or group take some way to communicate with each other, this communication aims to obtain payment or reward. Benefit sharing means that share the scenic areas and indigenous folk community of interests and responsibilities. To implement the integration strategy of tourism scenic spots and Aboriginal, relations can form symbiotic, mutually beneficial and win-win interconnection. For example "impression Sanjie Liu", "dynamic Yunnan" success lies in tourism companies and joint efforts of Aboriginal actor. No such as tourists, again good entertainment program also not long. The performing arts program arrangement to the tourism resources as the basis, performing arts project marketing is inseparable from the promotion and tourism enterprises. Mature tourism system depends on the parties between docking and cooperation promotion, profit sharing, establishing the mechanism of risk sharing and benefits sharing.

iii) To popularize and improve the residents cultural level, strengthen the consciousness of protecting environment, cultural relics. But more important is to establish indigenous master consciousness. Improve residents cultural level of protection, improve the Protect environment protection concept residents through training, lectures, absorption with residents must ecological protection skills involved in ecological tourism decision-making and management work, priority area residents' employment, let the residents have a sense of ownership, the management organizations and local community com., give full play to the important Cosplay protection of indigenous people in the tourism scenic area and development, to achieve substantive participation. At the same time, adhere to the education and training related to environmental protection laws and regulations and the knowledge and skills of residents, so that residents deeply aware of Protect environment is to protect her, care environment is to protect their homes, positive ideas consciously establish "full protection", become the main power to protect scenic reserve. The residents themselves to maintain the local natural environment, urging tourists to the natural environment destruction and pollution in tourist activities of the formation of the environmental protection act, a good social atmosphere. At the same time, in the process of eco-tourism strengthen biodiversity and ecological environmental protection education to visitors, give full play to the function of ecological education of ecological tourism. To realize the nature reserve is to protect the biological diversity and the natural heritage of the purpose, to meet the current and future generations of fair use of biological resource demand, in order to ensure the sustainable development of scenic areas.

iv) The aboriginal village as the major scenic spots in the small scenic spot to design, management, operation. Mining the old village of historical and cultural heritage. Aboriginal is part of scenic spots in the life. To effectively use their power and active elements, the village and the aborigines become attract tourists, improve the window promote scenic culture grade of the spiritual realm. Disadvantaged aboriginal culture in the face of modernity generated strong culture, may be difficult to hold the line, will gradually retreated to the edge. Tourism enterprises using the economic capital of aboriginal cultural capital to build, the formation of a strong "local culture to attract tourists. In the market economy of the ship, the humanities tourism resources or be transformed into a tool to make money or dissimilated as the tourism game items, all kinds of "new" way of life, all kinds of bad or brilliant ancient human reproduction in different ways and in different degree of damage with the humanities tourism resources. Only the native culture has been continuously strengthened in the process of travel, sustainable development can be achieved only culture. Tourism enterprises should respect of the local aboriginal ethnic customs and religious culture, in the culture of re creation and reproduction to avoid cultural resources into one-off exchange goods. Is indigenous culture owners, owners, the specific investment on the culture of interest returns, can we co-existence. 


\section{Conclusion}

Scenic area has the inestimable aesthetic, scientific, historical, cultural value, any person including the area residents have the obligation to protect scenic resources. However, scenic area residents rights can not be ignored. Only when the rights and interests of the citizens get effective guarantee, the residents would be more willing to actively cooperate with the management of scenic spots, the implementation is conducive to the protection of scenic and historical resources act. Therefore, we should be in line with the principles of fairness and reasonableness, adopt various ways and means of maintaining the rights and interests of area residents, and conflict with the protection of the rights and interests of the residents used to coordinate the protection of scenic areas, the ultimate realization of scenic spots in our country according to the law protection, scientific management and sustainable use.

\section{Acknowledgements}

The research work was supported by the Department of higher education of Guangdong Province outstanding youth teacher training program funded project under Grant No. Yq2013176 and Zhuhai Social Science Association project under Grant No. 2014084.

\section{References}

[1] Wang Shufang.China's scenic area and the original residents of the harmonious development model to investigate the .J.human geography.03, (2010).65-68.

[2] Luo Tingting.the Mount Huangshan scenic area community issues and community planning of.D.master's degree paper of Tsinghua University. 2004.

[3] Hu Yang. Related social problems in Mount Lu scenic area of integrated planning approach of Mount Lu social regulation of.D. study based on the special master's degree thesis of Tsinghua University. 2005.

[4] Yang Yumei. The exploration of the relationship between governance .J. economic problems of tourism enterprises and Aboriginal.04, (2011).25-28.

[5] Wang Ying. The local cultural characteristics of the city street landscape design and research of. Xi'an University Of Architecture And Technology. (2004).108-118.

[6] Wu Tiehong. New city tourism image design .J. Journal of Inner Mongolia normal university.05, (2007).71-75..

[7] Eagles,P.F.J. Environmental Management in Parks.P Dearden, R.Rollins. Parks and Protected Areas in Canada: Planning and Management.Oxford,Oxford University Press. (1993).154-184.

[8] Yu Kongjian \& Li Dihua. The ecological design for landscape and city: the concept and principle of.J.Chinese garden.06, (2001).21-24. 